American Journal of Environmental Sciences 7 (5): 456-462, 2011

ISSN 1553-345X

(C) 2011 Science Publications

\title{
Geo-Spatial Technologies for Carbon Sequestration Monitoring and Management
}

\author{
${ }^{1}$ Jeyanny, V., ${ }^{2}$ S.K. Balasundram and ${ }^{3}$ M.H.A. Husni \\ ${ }^{1}$ Forest Plantation Program, \\ Forest Research Institute of Malaysia 52109, Kepong, Selangor, Malaysia \\ ${ }^{2}$ Department of Agriculture Technology, \\ Faculty of Agriculture, Universiti Putra Malaysia, 43400 Serdang, Selangor, Malaysia \\ ${ }^{3}$ Department of Land Management, \\ Faculty of Agriculture, Universiti Putra Malaysia, 43400 Serdang, Selangor, Malaysia
}

\begin{abstract}
Problem statement: Globally, the quantification of Carbon Sequestration (CS) potential of various ecosystems was a challenge. There was an urgent need for technologies that can quantify CS potential cost-efficiently in a repeated and organized manner. Approach: Remote Sensing (RS) and Geographic Information System (GIS) had great potential in current estimation, future prediction and management of carbon sequestration potential in terrestrial ecosystems. This review discusses the current utilization of RS and GIS technologies in CS management in various sectors. Results: Deployment of RS and GIS for CS sequestration improves accuracy, reduces costs, increases productivity and provides current observations from a regional scale. Conclusion: This review demonstrates the synergistic role of RS and GIS technologies in improving CS management.
\end{abstract}

Key words: Remote Sensing (RS), Geographic Information System (GIS), Carbon Sequestration (CS), Precision Agriculture (PA), Decision Support System (DSS),

\section{INTRODUCTION}

Climate change is one of the greatest challenges of our time. According to the National Oceanic and Atmospheric Administration of the USA, concentration of $\mathrm{CO}_{2}$ in the atmosphere has steadily increased from $280 \mathrm{ppm}$ in 1800 to $385 \mathrm{ppm}$ in 2008 . This increase has apparently triggered global temperature rise, causing a great deal of discomfort to the world population. The northern hemisphere and the European region are witnessing the disappearance of ice, permafrost, forest fires and fatal heat waves. The southern hemisphere and the Asian region are encountering storms and floods due to overflowing rivers and increased precipitation. Deep and excruciating scars are left behind by natural disasters, affecting the livelihood of various communities. New approaches in climate change mitigation efforts are becoming more important. One such effort is the quantification of Carbon Sequestration (CS) potential of various ecosystems. $\mathrm{CS}$ is the process of transfer and secure storage of atmospheric $\mathrm{CO}_{2}$ into other long-lived carbon pools that would otherwise be emitted or remain in the atmosphere (Lal, 2007). Terrestrial carbon sinks include natural forests, plantation forests, wetlands and the soil biome. Quantification and management of CS in a regional scale would involve the deployment of cutting edge geo-spatial technologies, which are routinely used in Precision Agriculture (PA). PA involves site- and time-specific management of agricultural systems, based on integrated technologies which are able to determine the inputs needed based on localized variations (Balasundram et al., 2007). The objectives of PA are to maximize net benefits, in terms of economic, environmental and social goals of the enterprise. PA is enabled by geo-spatial technologies such as geographic information system, global positioning system, optical and proximal remote sensing, geostatistics, artificial neural networks and variable rate technology. These tools can be used in varying configurations to quantify soil status, climatic patterns and crop growth of a certain agricultural system and thrives to lower the production cost by finetuning seeding, fertilizer, chemical and water use, which potentially increases production volume and lowers costs (Balasundram et al., 2006a; 2006b). These technologies can be potentially used in varying levels of integration for monitoring and management of CS. One

Corresponding Author: S.K. Balasundram, Department of Agriculture Technology, Universiti Putra Malaysia, 43400 Serdang, Selangor, Malaysia. 
such approach that is gaining credence in ecological and environmental applications is the integration of remote sensing and geographical information system.

\section{MATERIALS AND METHODS}

Remote sensing: Remote Sensing (RS) is the science of obtaining and interpreting information from a distance, using sensors that are not in physical contact with the objects of interest whereas Geographical Information System (GIS) is a system of hardware, software, procedure and personnel to facilitate the management, manipulation, analysis, modeling, representation and display of geo-referenced data to solve complex problems regarding planning and management of resources (Star and Estes, 1990). In principle, RS measures the amount of visible and nonvisible radiation reflected from the target surface and is expressed as spectral reflectance Fig. 1. RS platforms include satellites, aircrafts and ground base sensors which can be divided to passive and active sensing. Passive sensors rely on natural source of radiation (i.e., sun) while active sensors generate their own radiation to illuminate its target. RS captures images using multiple stations, bands, dates, stages and polarization and these images can be unified to produce enhanced composite images for analysis, to obtain whole and precise information.

Integration of RS data with GIS: Current RS technology offers acquisition and analysis of georeferenced data from assorted platforms and can be operationally linked with spatial data layers and models within a GIS. The effortless ability of integrating RS data with other sources of information makes geospatial technology a powerful contemporary instrument (Kohl et al., 2006). Likewise, GIS collects and pre-processes spatial data from various sources. It provides the utilities to manage attribute data, location and topology in spatial analyses. Neither RS nor GIS can reach their full potential unless the two technologies are fundamentally linked. At present time, both technologies have revolutionized the facade of modern farming. The interactions of these components were summarized by Wilkinson (1996) as follows:

- RS data can be used as input for analysis within a GIS

- GIS can provide ancillary data for improved RS analysis for discrimination of ecosystem types, land cover and land use classes

- The application of RS and other spatial data within a GIS provides capabilities for modeling and scenario analysis

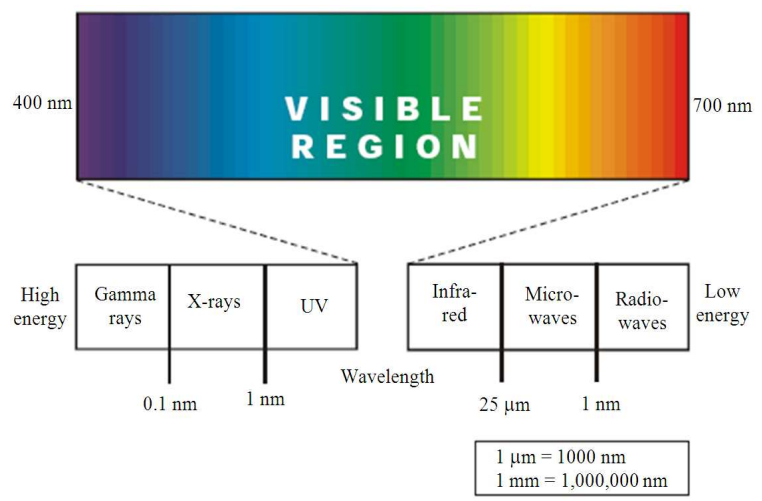

Fig. 1: The visible region within the electromagnetic spectrum, ranging between 400 and $700 \mathrm{~nm}$ (Nowatzki et al., 2004)

\section{RESULTS}

Recent agro-ecological applications of integrated RS-GIS: The integrated RS-GIS approach is well explored and studied in precision farming (Liaghat and Balasundram, 2010; Fitzgerald et al., 2006; Seelan et al., 2003), aquaculture (Nath et al., 2000), crop cultivation (Lopez-Lozano et al., 2010), plant nutrient management (Goel et al., 2003), forest inventory (Kohl et al., 2006), erosion control (Mati et al., 2000; Ramos et al., 2007), mountain survey (Mulders, 2001), township planning, hydromorphological studies (Chandra and Ghosh, 2006), coastal zone management and assessment of biomass potential from agricultural wastes (Voivontas et al., 2001).

In Malaysia, the integrated RS-GIS approach has been employed for evaluation of oil palm crop performance indicators such as inventory of trees phenology, macro-nutrient assessment and replanting (Loh et al., 2009). Various workers have exploited high resolution RS platform such as Synthetic Aperture Radar (SAR) and optical sensors for estimation of standing timber volume in forestry .

In Spain, the combined use of Quickbird satellite imagery and digital soil maps facilitated detection of differences in abiotic stress associated with soil sodicity in a 60 ha corn field. Variable rate application based on spatial variability was recommended for operations such as irrigation, fertilization and liming (LopezLozano et al., 2010). In Canada, hyperspectral observations using a Compact Airborne Spectrographic Imager (CASI) showed that the spectral reflectance of corn is significantly influenced by weed infestation levels and nitrogen rates (Goel et al., 2003). 
Integrated RS-GIS for carbon sequestration management and monitoring: Since the Kyoto Protocol, development of Carbon Sequestration (CS) strategies has become a global priority. The Intergovernmental Panel on Climate Change (IPCC) via its Good Practice Guidance Framework encourages the implementation of models and inventory measurement systems that are tailored to address national circumstances. Such models and systems should be driven by high resolution activity data which are disaggregated at sub-national level to fine grid-scales (Goetz et al., 2009).

The strength of integrated RS-GIS rests on its ability to perform advanced spatial and/or temporal analysis on multiple layers of high resolution information. This facilitates research efforts directed at managing the global carbon cycle, mainly by providing value-added information and assisting implementation procedures. Integrated RS-GIS can act as a Decision Support System (DSS) tool in CS management and monitoring.

Integrated RS-GIS enables quantification of spatial and temporal variability of climate and soil conditions across a region (Niu and Duiker, 2006). In the long term, the deployment of RS-GIS is envisaged to exhibit cost- and time-effectiveness (Updegraff et al., 2005) due to its ability to delineate uncertainties (Patenaude et al., 2004), to improve observational accuracy (Gamon et al., 2004) and to allow rapid data acquisition from a wide regional coverage in a nondestructive manner (Chandra and Ghosh, 2006).

Effective use of RS is contingent on ground truthing and sampling strategies so as to capture spatial and or temporal variability at the optimum scale (Fitzgerald et al., 2006). RS tools such as Synthetic Aperture Radar (SAR), Light Duetection and Ranging (LiDaR) and satellite sensors such as Landsat, SPOT and Ikonos have been used to map carbon stocks (Goetz et al., 2009). In the Huang Hai Plain of China, soil databases were combined with weather records to create eighteen EPIC (Environmental Policy Integrated Climate) models to generate climate change predictions for agricultural cropping systems. It was found that the total soil CS potential in the area, double cropped with wheat-corn under a conventional tillage system, would range from $0.16-0.43 \mathrm{Pg}$ of $\mathrm{C}$ without any significant impact on crop yields (Thomson et al., 2006). In a recent investigation to model soil CS potential in eroded areas, the relationship of soil CS potential with soil erosion type, altitude, soil type and soil parent material were explored using a GIS (Shi et al., 2009). This study showed that recovery of vegetation increases CS potential of eroded soils. Regional-scale GIS has been used as the operating platform in the development of C-Lock, a new system that standardizes estimation of agricultural carbon sequestration credits. This system incorporates CENTURY, a biogeochemical model that simulates carbon, nutrient and water dynamics for different types of ecosystems. Such a system facilitates precision carbon management, an emerging frontier of applied science.

Besides the agriculture sector, deployment of geospatial technologies for CS management has also been documented in the forestry sector. Caldwell et al. (2007) illustrated the complexity of Afforestation and Reforestation (A/R) programs in China using an integrated assessment approach based on RS-GIS. A/R programs are aimed at increasing $\mathrm{CS}$ and improving biodiversity. Their integrated assessment model comprised sub models, qualitative assessment modules, processed scenarios and final outputs for income rates Fig. 2. The A/R program gave farmers income benefits in terms of financial support for the first 8 years. However, it was predicted that in the long term when subsidies are halted farmers would experience income loss.

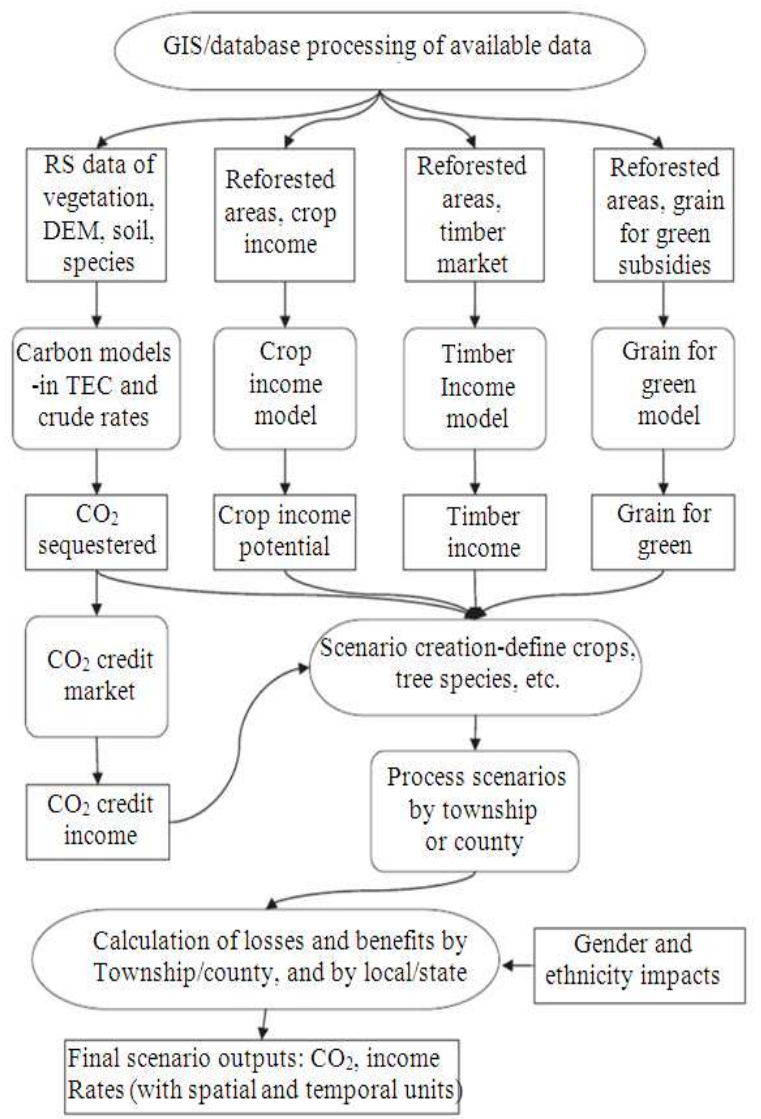

Fig. 2: An integrated assessment model based on RSGIS (Caldwell et al., 2007) 
In the USA, Niu and Duiker (2006) reported that Landsat imagery integrated into a GIS was used to identify hotspots (i.e., high CS capacity locations) for afforestation programs in the USA. This approach enabled the prediction of potential CS capacity as a result of afforestation for 20-50 years. Using a similar approach, it is predicted that afforestation efforts in Latin America may generate up to USD2.3 billion worth of carbon credits in the next 20 years (Benitez and Obersteiner, 2006). In Ukraine, NOAA AVHRR imagery and mathematical models were used to estimate the total amount of carbon released due to the forest fires and the subsequent loss of CS capacity (Volosko-Demkiv and Ryabokonenko, 2005).

\section{DISCUSSION}

Information about CS capacity and estimation of carbon credits in a regional scale will assist policy makers in outlining effective measures for best carbon management practices in the current and future era. There is a steady accumulation of literature on the application of RS, GIS or both in CS management of forests (Benitez and Obersteiner, 2006; Campbell et al., 2008; Chen et al., 2007; Neilson et al., 2007; Upadhyay et al., 2006), land use change (Inoue et al., 2010; Schaldach and Alcamo, 2006; Tornquist et al., 2009; Upadhyay et al., 2005) and croplands (McCarty et al., 2007; Watts et al., 2009). The application of RS platform such as Landsat was found to assist in classifying crops according to their CS potential by verifying and documenting crop rotations and cropping intensity (Bricklemyer et al., 2007). Wang et al., (2010) used an integrated RS-GIS approach to investigate CS potential in above and below-ground sinks of local forests in the Guizhou Province of China.

Spectrally-based Normalized Difference Vegetation Index (NDVI) and other vegetation indices, derived from RS platforms, are common indicators used to monitor biophysical conditions and vegetation cover. These indices are solely designed to optimize the spectral signatures of vegetation and to minimize the influence of soil reflectance and atmospheric attenuation (Patenaude et al., 2005). In Northern Kazakhstan, the NOAA satellite imagery, GIS data layers and NDVI measurements were manipulated to estimate $\mathrm{CO}_{2}$ sequestration in cereal crop fields and grassland (Sultangazin et al., 2007).

The combined use of biomass models and NDVI data has simplified estimation of carbon stocks in boreal and temperate forests (Dong et al., 2003), Atlantic rainforests (Freitas et al., 2005), peat swamp forests (Gandaseca et al., 2009) croplands (Watts et al.,
2009; Yan et al., 2007), biologic soil crusts (Burgheimer et al., 2006), bamboo stands (Du et al., 2010) and semi arid rangelands (Nosetto et al., 2006).

Recently, the United States Department of Energy established a nationwide network in an effort to implement appropriate strategies to promote CS in different regions across the nation (Litynski et al., 2008; Ruby, 2005). This study deployed GIS as a fundamental tool in managing information about $\mathrm{CO}_{2}$ sources, feasible sequestration sites, relevant infrastructure and related factors in each region. GIS was also used as a DSS to screen potential storage formations, suitable transportation, source to sink matching and potential risk management solutions (Litynski et al., 2006). This effort led to the GIS-based National Carbon Sequestration Database (NatCarb) which provides a national view of the carbon capture and storage potential in the United States and Canada (Carr et al., 2009).

Quantification and estimation of spatially explicit services for CS potential may differ based on climate, management applications, history, ecosystem, species and the local communities. A case by case scenario will be most effective in producing reliable data using the RS-GIS integration. Currently, scientists are designing specific models to improve the precision of carbon stock estimates that changes through time (Goetz et al., 2009). Meanwhile, the voids in computing net primary productivity, depth distribution of biomass carbon, relationship between litter and carbon pools and belowground (roots and microbes) sequestration (Lal, 2007) need to be strategically addressed if reporting of CS potential and trading of carbon credits are carried out based on geo-spatial technologies. Limited expertise and resources in developing countries necessitate knowledge sharing and cross-boundary collaboration in Reducing Emissions from Deforestation and Degradation (REDD) projects. In addition, cyber infrastructure that integrates computing environment and capabilities, should be enhanced. This would costeffectively improve access to specific information, models, problem solving capacities and communication (Rich et al., 2008) in developing countries.

\section{CONCLUSION}

The synergistic role of RS and GIS technologies in CS management was synthesized. Numerous literature reports suggest that the integrated RS-GIS approach can aid CS management and monitoring strategies. In climate change mitigation, this approach can provide an efficient and cost-effective means of estimating aboveand below-ground biomass, delineating spatial variability, predicting potential carbon stocks and 
revenues and outlining appropriate management strategies for localized and regional scale. In the near future, the deployment of an integrated RS-GIS approach for precision carbon management will become more visible.

\section{REFERENCES}

Balasundram, S.K., D.J. Mulla and P.C. Robert, 2006a. Accounting for spatial variability in a short-term fertilizer trial for oil palm. Int. J. Soil Sci., 1: 184195. DOI: 10.3923/ijss.2006.184.195

Balasundram, S.K., P.C. Robert, D.J. Mulla and D.L. Allan, 2006b. Relationship between oil palm yield and soil fertility as affected by topography in an indonesian plantation. Commun. Soil Sci. Plant Anal., 37: 1321-1337. DOI: 10.1080/00103620600626817

Balasundram, S.K., D.J. Mulla and P.C. Robert, 2007. Spatial data calibration for site-specific phosphorus management. Int. J. Agric. Res., 2: 888-899. DOI: 10.3923/ijar.2007.888.899

Benitez, P.C. and M. Obersteiner, 2006. Site identification for carbon sequestration in Latin America: A grid-based economic approach. For. Pol. Econ., 8: 636-651. DOI: 10.1016/j.forpol.2004.12.003

Bricklemyer, R.S., R.L. Lawrence, P.R. Miller and N. Battogtokh, 2007. Monitoring and verifying agricultural practices related to soil carbon sequestration with satellite imagery. Agric. Econ. Environ., 118: 201-210. DOI: 10.1016/j.agee.2006.05.017

Burgheimer, J., B. Wilske, K. Maseyk, A. Karnieli and E. Zaady et al., 2006. Relationships between normalized difference vegetation index (NDVI) and carbon fluxes of biologic soil crusts assessed by ground measurements. J. Arid Environ., 64: 651-669. DOI: 10.1016/j.jaridenv.2005.06.025

Caldwell, I.M., V.W. Maclaren, J.M. Chen, W.M. Ju and S. Zhou et al., 2007. An integrated assessment model of carbon sequestration benefits: A case study of Liping county, China. J. Environ. Manag., 85: 757-773. DOI: 10.1016/j.jenvman.2006.08.020

Campbell, J.E., J.C. Moen, R.A. Ney and J.L. Schnoor, 2008. Comparison of regression coefficient and GIS-based methodologies for regional estimates of forest soil carbon stocks. Environ. Poll., 152: 267273. DOI: 10.1016/j.envpol.2007.06.057

Carr, T.R., A. Iqbal, N. Callaghan, Dana-AdkinsHeljeson and K. Look et al., 2009. A national look at carbon capture and storage-National carbon sequestration database and geographical information system (NatCarb). Ene. Procedia., 1: 2841-2847. DOI: 10.1016/j.egypro.2009.02.057
Chandra, A.M. and S.K. Ghosh, 2006. Remote Sensing and Geographic Information System. 1st Edn., Alpha Science, Oxford, ISBN: 1842652788, pp: 298.

Chen, J.M., S.C. Thomas, Y. Yin, V. Maclaren and J. Liu et al., 2007. Enhancing forest carbon sequestration in China: Toward an integration of scientific and socio-economic perspectives. J. Environ. Manag., 85: 515-523. DOI: 10.1016/j.jenvman.2006.08.019

Dong, J., R.K. Kaufmann, R.B. Myneni, C.J. Tucker and P.E. Kauppi et al., 2003. Remote sensing estimates of boreal and temperate forest woody biomass: carbon pools, sources and sinks. Remo. Sens. Environ., 84: 393-410. DOI: 10.1016/S00344257(02)00130-X

Du, H., R. Cui, G. Zhou, Y. Shi and X. Xu et al., 2010. The responses of Moso bamboo (Phyllostachys heterocycla var. pubescens) forest aboveground biomass to Landsat TM spectral reflectance and NDVI. Acta Ecol. Sin., 30: 257-263. DOI: 10.1016/j.chnaes.2010.08.005

Fitzgerald, G.J., S.M. Lesch, E.M. Barnes and W.E. Luckett 2006. Directed sampling using remote sensing with a response surface sampling design for site-specific agriculture. Comput. Elect. Agric., 53: 98-112. DOI: 10.1016/j.compag.2006.04.003

Freitas, S.R., M.C.S. Mello and C.B.M. Cruz, 2005. Relationships between forest structure and vegetation indices in Atlantic Rainforest. For. Ecol. Manag., 218: 353-362. DOI: 10.1016/j.foreco.2005.08.036

Gamon, J.A., K.F. Huemmrich, D.R. Peddle, J. Chen and D. Fuentes et al., 2004. Remote sensing in BOREAS: Lessons learned. Rem. Sens. Environ., 89: 139-162. DOI: 10.1016/j.rse.2003.08.017

Gandaseca, S., J. Sabang, O.H. Ahmed and N.M.A. Majid, 2009. Vegetation assessment of peat swamp forest using remote sensing. Am. J. Agric. Biol. Sci., $\quad 4$ : 167-172. DOI: 10.3844/ajabssp.2009.167.172

Goel, P.K., S.O. Prasher, J.A. Landry, R.M. Patel and R.B. Bonnell et al., 2003. Potential of airborne hyperspectral remote sensing to detect nitrogen deficiency and weed infestation in corn. Comput. Elect. Agric., 38: 99-124. DOI: 10.1016/S01681699(02)00138-2

Goetz, S.J., A. Baccini, N.T. Laporte, T. Johns and W. Walker et al., 2009. Mapping and monitoring carbon stocks with satellite observations: A comparison of methods. Carbon Bal. Manag., 4: 22. DOI: $10.1186 / 1750-0680-4-2$ 
Inoue, Y., Y. Kiyono, H. Asai, Y. Ochiai and J. Qi et al., 2010. Assessing land-use and carbon stock in slash-and-burn ecosystems in tropical mountain of Laos based on time-series satellite images. Int. J. Applied Earth Obser. Geoinfo., 12: 287-297. DOI: 10.1016/j.jag.2010.04.004

Kohl, M., S. Magnussen and M. Marchetti, 2006. Sampling Methods: Remote Sensing and GIS Multiresource Forest Inventory. 1st Edn., Springer, Berlin, ISBN: 3540325719, pp: 373.

Lal, R., 2007. Researchable Priorities in Terrestrial Carbon Sequestration in Central Asia. In: Climate Change and Terrestrial Carbon Sequestration in Central Asia, Lal, R., B.A. Stewart, D.O. Hansen and P. Doraiswamy (Eds.). Routledge, London, ISBN: 0415422353, pp: 475-484.

Liaghat, S. and S.K. Balasundram, 2010. A review: The role of remote sensing in precision agriculture. Am. J. Agric. Biol. Sci., 5: 50-55. DOI: 10.3844/ajabssp.2010.50.55

Litynski, J.T., S.M. Klara, H.G. McIlvried and R.D. Srivastava, 2006. The United States Department of Energy's regional carbon sequestration partnerships program: A collaborative approach to carbon management. Environ. Int., 32: 128-144. DOI: 10.1016/j.envint.2005.05.047

Litynski, J.T., S. Plasynski, H.G. McIlvried, C. Mahoney and R.D. Srivastava, 2008. The United States Department of Energy's regional carbon sequestration partnerships program validation phase. Environ. Int., 34: 127-138. DOI: 10.1016/j.envint.2007.07.005

Loh, K.F., P. Ragu, M. Shattri and I. Jamil, 2009. A spatial decision support tool for oil palm plantation management. Pertanika J. Sci. Technol.

Lopez-Lozano, R., M.A. Casterad and J. Herrero, 2010. Site-specific management units in a commercial maize plot delineated using very high resolution remote sensing and soil properties mapping. Comput. Elect. Agric., 73: 219-229. DOI: 10.1016/j.compag.2010.04.011

Mati, B.M., R.P.C. Morgan, F.N. Gichuki, J.N. Quinton and T.R. Brewer et al., 2000. Assessment of erosion hazard with the USLE and GIS: a case study of the upper Ewaso Ng'iro North basin of Kenya. Int. J. Appl. Earth Obser. Geoinfo., 2: 7886. DOI: 10.1016/S0303-2434(00)85002-3

McCarty, G., P. Doraiswamy, B. Akhmedou and K. Pachikin, 2007. Potential for Soil Carbon Sequestration in Central Kazakhstan. In: Climate Change and Terrestrial Carbon Sequestration in Central Asia, Lal, R., B.A. Stewart, D.O. Hansen and P. Doraiswamy (Eds.). Routledge, London, ISBN: 0415422353, pp: 413-418.
Mulders, M.A., 2001. Advances in the application of remote sensing and GIS for surveying mountainous land. Int. J. Applied Earth Obser. Geoinfo., 3: 310. DOI: 10.1016/S0303-2434(01)85015-7

Nath, S.S., J.P. Bolte, L.G. Ross and J. AguilarManjarrez, 2000. Applications of Geographical Information Systems (GIS) for spatial decision support in aquaculture. Aquac. Eng., 23: 233-278. DOI: 10.1016/S0144-8609(00)00051-0

Neilson, E.T., D.A. MacLean, F.R. Meng and P.A. Arp, 2007. Spatial distribution of carbon in natural and managed stands in an industrial forest in New Brunswick, Canada. For. Ecol. Manag., 253: 148160. DOI: 10.1016/j.foreco.2007.07.017

Niu, X. and S.W. Duiker, 2006. Carbon sequestration potential by afforestation of marginal agricultural land in the Midwestern U.S. For. Ecol. Manag., 223: 415-427. DOI: 10.1016/j.foreco.2005.12.044

Nosetto, M.D., E.G. Jobbagy and J.M. Paruelo, 2006. Carbon sequestration in semi-arid rangelands: Comparison of Pinus ponderosa plantations and grazing exclusion in NW patagonia. J. Arid. Environ., 67: 142-156. DOI: 10.1016/j.jaridenv.2005.12.008

Nowatzki, J.F., R. Andres and K. Kyllo, 2004. Agricultural Remote Sensing Basics. 1st Edn., NDSU Extension Service, Fargo, pp: 4.

Patenaude, G., R.A. Hill, R. Milne, D.L.A. Gaveau and B.B.J. Briggs, et al., 2004. Quantifying forest above ground carbon content using LiDAR remote sensing. Rem. Sens. Environ., 93: 368-380. DOI: 10.1016/j.rse.2004.07.016

Patenaude, G., R. Milne and T.P. Dawson, 2005. Synthesis of remote sensing approaches for forest carbon estimation: Reporting to the Kyoto Protocol. Environ. Sci. Pol., 8: 161-178. DOI: 10.1016/j.envsci.2004.12.010

Ramos, M.I., A.J. Gil, F.R. Feito and A. Garcia-Ferrer, 2007. Using GPS and GIS tools to monitor olive tree movements. Comput. Elect. Agric., 57: 135148. DOI: 10.1016/j.compag.2007.03.003

Rich, P.M., J.S. Bollinger, B. Bhaduriand and D.R. Bleakly, 2008. Perspective on Department of Energy geospatial science. J. Map. Geog. Libr., 4: 29-58. DOI: 10.1300/J230v04n01_03

Ruby, J., 2005. $\mathrm{CO}_{2}$ separation, capture and transport issues for the west coast regional carbon sequestration partnership. Nexant Inc.

Schaldach, R. and J. Alcamo, 2006. Coupled simulation of regional land use change and soil carbon sequestration: A case study for the state of Hesse in Germany. Environ. Model. Soft., 21: 1430-1446. DOI: $10.1016 /$ j.envsoft.2005.07.005 
Seelan, S.K., S. Laguette, G.M. Casady and G.A. Seielstad, 2003. Remote sensing applications for precision agriculture: A learning community approach. Rem. Sens. Environ., 88: 157-169. DOI: 10.1016/j.rse.2003.04.007

Shi, X.Z., H.J. Wang, D.S. Yu, D.C. Weindorf and X.F. Cheng et al., 2009. Potential for soil carbon sequestration of eroded areas in subtropical China. Soil Till. Res., 105: 322-327. DOI: 10.1016/j.still.2008.12.016

Star, J. and J. Estes, 1990. Geographic Information Systems: An Introduction. 1st Edn., Prentice Hall, New Jersey, USA., ISBN-10: 0133511235, pp: 303.

Sultangazin, U., N. Muratova and A. Terekhov, 2007. Remote Sensing Application for Mapping Terrestrial Carbon Sequestration in Kazakhstan. In: Climate Change and Terrestrial Carbon Sequestration in Central Asia, Lal, R., B.A. Stewart, D.O. Hansen and P. Doraiswamy (Eds.), ISBN: 0415422353, Routledge, London, pp: 429440.

Thomson, A.M., R.C. Izaurralde, N.J. Rosenberg and X. He, 2006. Climate change impacts on agriculture and soil carbon sequestration potential in the Huang-Hai Plain of China. Agric. Ecosyst. Environ., 114: 195-209. DOI: 10.1016/j.agee.2005.11.001

Tornquist, C.G., P.W. Gassman, J. Mielniczuk, E. Giasson and T. Campbell, 2009. Spatially explicit simulations of soil C dynamics in Southern Brazil: integrating Century and GIS with i_Century. Geoderma, 150: 404-414. DOI: 10.1016/j.geoderma.2009.03.001

Upadhyay, T.P., B. Solberg and P.L. Sankhayan, 2005. A review of carbon sequestration dynamics in the Himalayan region as a function of land-use change and forest/soil degradation with special reference to Nepal. Agric. Ecosyst. Environ., 105: 449-465. DOI: 10.1016/j.agee.2004.09.007
Upadhyay, T.P., B. Solberg and P.L. Sankhayan, 2006. Use of models to analyse land-use changes, forest/soil degradation and carbon sequestration with special reference to Himalayan region: A review and analysis. For. Pol. Econ., 9: 349-371. DOI: 10.1016/j.forpol.2005.10.003

Updegraff, K., P.R. Zimmerman, M. Price and W.J. Capehart, 2005. C-Lock: An online system to standardize the estimation of agricultural carbon sequestration credits. Fuel Process. Technol., 86: 1695-1704. DOI: 10.1016/j.fuproc.2005.01.010

Voivontas, D., D. Assimacopoulos and E.G. Koukios, 2001. Aessessment of biomass potential for power production: a GIS based method. Biom. Bioenergy, 20: 101-112. DOI: 10.1016/S0961-9534(00)000702

Volosko-Demkiv, O. and O. Ryabokonenko, 2005. Application of GIS and remote sensing technologies for assessing $\mathrm{CO}_{2}$ capture and transmission. Ukrainiam Land and Resource Management Center.

Wang, J., J. Chen, W. Ju and M. Li, 2010. IA-SDSS: A GIS-based land use decision support system with consideration of carbon sequestration. Environ. Model. Softw., 25: 539-553. DOI: 10.1016/j.envsoft.2009.09.010

Watts, J.D., R.L. Lawrence, P.R. Miller and C. Montagne, 2009. Monitoring of cropland practices for carbon sequestration purposes in north central Montana by Landsat remote sensing. Rem. Sens. Environ., 113: 1843-1852. DOI: 10.1016/j.rse.2009.04.015

Wilkinson, G.G., 1996. A review of current issues in the integration of GIS and remote sensing data. Int. J. Geog. Inform. Syst., 10: 85-101. DOI: 10.1080/02693799608902068

Yan, H., M. Cao, J. Liu and B. Tao, 2007. Potential and sustainability for carbon sequestration with improved soil management in agricultural soils of China. Agric. Ecosyst. Environ., 121: 325-335. DOI: $10.1016 /$ j.agee.2006.11.008 